\title{
Corrigendum
}

\section{Correction: Nerve Conduction Study of the Distal Branches of the Superficial Radial Nerve}

\author{
Hye Ryoung Bun, MD, Mi Ryoung Hwang, MD, Dong Hwee Kim, MD, Eu Ha Kwon, MD \\ Department of Rehabilitation Medicine, Korea University College of Medicine, Seoul, Korea
}

http://www.e-arm.org/journal/view.html?uid=3209

J Korean Acad Rehab Med 2007;31(5):557-561

To the Editor,

We found that the fourth author's name was published incorrectly. "Eu Ha Kwon" was changed to "You Ha Kwon". Also the department name have been mistakenly recorded in the affiliation. The statement is hereby corrected as:

Department of Physical Medicine \& Rehabilitation, Korea University College of Medicine, Seoul, Korea

We apologize for any inconvenience that this may have caused.

Yours sincerely,

You Ha Kwon

(E-mail: director@tsprs.com)

(a) This is an open-access article distributed under the terms of the Creative Commons Attribution Non-Commercial License (http://creativecommons.org/ licenses/by-nc/4.0) which permits unrestricted noncommercial use, distribution, and reproduction in any medium, provided the original work is properly cited. Copyright $\odot 2017$ by Korean Academy of Rehabilitation Medicine 